Advisory Committee on Ironstone Restoration. This Act necessited new regulations as follows:

Statutory Instrument 1972 No. 210:

'This Order prescribes the full and reduced rates of contributions to be paid by ironstone operators towards the Ironstone Restoration Fund under section 1 of the Mineral Workings Act 1971, in respect of ironstone extracted on or after 1 April 1971 and the sum which may be deducted from payments made under mining leases and mineral rights orders (in accordance with section 3 of that Act) in respect of full-rate contributions.'

\section{Statutory Instrument 1972 No. 211 :}

'Section 9 of the Mineral Workings Act 1951 provides that the rate of payments out of the Ironstone Restoration Fund to be made to ironstone operators in respect of the restoration of worked ironstone land in compliance with conditions of a planning permission shall represent the amount by which the estimated cost per acre of the work of restoration exceeds such sum per acre as the Minister may determine to be the standard rate. The Ironstone Restoration Fund (Standard Rate) Order 1955 determined that rate to be $£ 110$ per acre.

This Order made under section 3 of the Mineral Workings Act 1971 prescribes a new rate of $£ 260$ per acre in respect of all work completed after 31 March 1972.'

To date the total area of restored land in Northamptonshire alone, since the passing of the Mineral Workings Act 1951, exceeds 5,000 acres (2,010 hectares). In addition, restoration has taken place in other parts of the ironstone district in Leicestershire, Kesteven, Lindsey, Oxfordshire, and Rutland.

In presenting this paper, I trust that it has portrayed what can be achieved under present legislation in England. Returning derelict lands to agriculture and restoring the countryside in this densely-populated island is a policy that has already proved well worth pursuing, and the contents of this paper may be of interest to persons undertaking similar work in other countries where ironstone fields are found.

\title{
The International Association on Water Pollution Research (IAWPR)
}

This Association was founded in 1965 with the unanimous approval of official statutes which gave the following among its principal objectives at that time:

1. The establishment of an international body concerned with pollution research so as to contribute most effectively to the development of biological, chemical, and engineering, research on water pollution abatement and control.

2. To ensure a cooperative effort for the exchange of information and technological communication, and to organize international meetings on water pollution research and water quality protection.

3. To provide a scientific medium for the publication of research reports and activities of the Association.

The old statutes also open membership to national organizations duly constituted and subscribing to the statutes, to associated members (with no voting rights), and to individual members (also with no voting rights). The main bodies of the Association are the Governing Board, with full powers to set policy and steer the activities of the organization, and the Executive Committee, which manages the affairs of the Association in terms of the financial, administrative, and technical, authority delegated to it by the Governing Board.

Only a few countries were members of the Association at the time of its establishment, but over the years the membership has expanded to cover more than 21 countries representing geographically all the major inhabited regions of the world. It was therefore felt that the statutes should be revised and this was done by the Governing Board at a meeting held in February 1974.

The revised objectives broaden the scientific and technical scope of the Association by including, for instance, estuary and coastal water-quality problems, and by stressing education as well as promoting by all available means the practical application of research in engineering design, construction, operation, control and management of waste-water collection systems, and use of purification and reclamation plants, etc. Last but not least among the objectives of the Association is cooperation with other organizations in the environmental pollution field. The Association has become in fact within its relatively brief life a 'non-governmental organization in official relations with WHO and possibly other governmental organizations'.

The new statutes anticipate also new categories of members, such as sustaining members, student members, and honorary members, and mention that the journal Water Research is in fact becoming the official journal of the Association. They also prescribe the cost of the subscriptions and state that the Association will organize biennial international conferences, attendance at which will be open to all persons or representatives of organizations on payment of the appropriate registration fee. The Seventh Conference of the Association took place in Paris from 9-13 September 1974.

As compared with their predecessor, the new statutes go into much more detail regarding the composition, functions, and procedures, both of the Governing Board and of the Executive Committee. They also go further in determining the functions of the national committees which form the backbone of the Association membership.

The present President of the Association is Dr G. J. Stander, P.O. Box 395, Pretoria, South Africa, and the Executive Editor is Dr S. H. Jenkins, Registrar, IAWPR Birmingham Course, Upper Tame Main Drainage Authority, 156-170 Newhall Street, Birminghan, England.

Renato Pavanello, Chief Sanitary Engineer Division of Environmental Health

World Health Organization

1211 Geneva 27

Switzerland. 